\title{
When i watch world news tonight, i need a hug? preparing children emotionally in a scary world
}

\author{
Volume 9 Issue I - 2018 \\ Steven Richfield \\ Clinical Psychologist, Philadelphia, USA
}

\author{
Correspondence: Steven Richfield, Clinical Psychologist, \\ Philadelphia, USA, Tel 6I0-238-4450, \\ Email director@parentcoachcards.com
}

Received: August 31, 2016 | Published: January 04, 2018
A parent writes: With warm looming and terror threats broadcast on radio and television, our kids have started to ask questions. So far they haven't shown any ill effects but I'm not sure what to look for and how to prepare them. Any advice would be greatly appreciated!

Peter Jennings doesn't usually trigger displays of affection in our 10year old son but he did so last week. After watching the encapsulated news stories of battle preparations, code orange alert, and the public's efforts to safeguard their homes, our nation's troubles were crystal clear. When I heard, "When I watch World News Tonight, I need a hug," I hugged him but knew that Jesse, like millions of other American children, needed more than a hug; he needed preparation, management and mastery. These three words came to mind because they have been etched in since my graduate training in psychology. I remember the discussions about children facing medical procedures, recovering from car accidents, and other traumatic events. Over twenty years later, I turn to these same three steps as both father and child psychologist. I believe that it behoves us all as parents to prepare our children to cope with trauma of an entirely different scope. Trauma is a sudden and sharp assault on one's sense of safety and control. For children, today's trauma is embedded in the words and pictures that spread fear of tomorrow's events. As news of war and terror alerts filters into our homes and conversations, many children will experience some shattering of their security. Some children will no doubt be more traumatized than others. Preparing our children for these events offers them a framework for placing information into an understandable context. Managing the thoughts and feelings stirred by events involves helping them to distinguish misinformation, reassure themselves, and find comfort in close relationships and routines. Mastery of the emotional impact of the events is the mental process of reconciling the facts with feelings, so that life can go on, afterwards. Here are some coaching tips: Preparation begins with considering your child's unique sensitivities and predisposition. If world events tend to tip the emotional scales in the direction of sleeplessness, protracted worry and preoccupation, proceed cautiously. If, on the other hand, your child tends to exist in the bubble of childhood, seemingly insulated from world events, it may be possible to use this opportunity to expand his/her frame of reference. The following points are offered for your consideration with the caveat that your own knowledge of your child can be your best guide:

Think of preparation as a stable foundation upon which to place heavy feelings and jarring knowledge

Try introducing the subject of war by speaking of it in a context. Unfortunately, war has been necessary in the past to stop people whose beliefs harm large groups of people. Although our country doesn't wish for war, we turn to it as a way to stop those people whose beliefs and behaviors can harm us. Suggest that war is likely to happen again, and that may make them feel a lot of different feelings. Fear, anxiety, sadness, anger, and many other emotions may surface in many people who watch a war on television and listen to news broadcasts. Explain how these are normal reactions that will lessen by expressing their ideas and feelings and asking questions. Point out that they remain safe no matter what feelings they are having, and that when it's over, the plan is for our safety to be even stronger.

Think of management as the daily discussions you will have with your child to keep up with how events are affecting them

Even though you may decide to pursue the preparatory approach I advised, it will be important to supervise and manage the flow of information. If you decide to allow your child to watch news broadcasts, sit by their side and periodically ask them about their thoughts and feelings. For many children, the pictures will have greater impact because they can be more readily replayed in their minds. Encourage them to tell you what their peers have said about the conflict, so that you can correct distortions or deliberate falsifications. Separate fact from fiction, but place the truth in terms they can understand. Depending upon their age and readiness, point out cause and effect, the importance of truth and agreements, and other lessons to be learned. Help them access their intellect rather than fall prey to their emotions.

Think of mastery as a way of tying off the loose ends of feelings so that the usual sense of safety and control can return

When our country is on the other side of this conflict, some kids will need further help. Some will not just drop the discussion, although most children will gladly do so. Periodically ask them if they are still having feelings or questions about what happened. Point out that it's okay to keep talking, and that you don't want them to keep those 
thoughts trapped inside. Those children who have been especially shaken by events should return to normal sleep and behavior patterns within a couple of weeks. If this isn't the case, or other troubling reactions persist, consult with a qualified professional.

\section{Acknowledgements}

None.

\section{Conflicts of interest}

Author declares there are no conflicts of interest.

Funding

None. 